OPEN ACCESS

Edited by:

Peter B. Marschik,

University Medical Center

Göttingen, Germany

Reviewed by:

Anders Dechsling,

Østfold University College, Norway

Preeti Jacob,

National Institute of Mental Health and

Neurosciences (NIMHANS), India

${ }^{*}$ Correspondence: Eva Möhler

eva.moehler@uks.eu

Specialty section: This article was submitted to Child and Adolescent Psychiatry, a section of the journal

Frontiers in Psychiatry

Received: 29 March 2021

Accepted: 05 July 2021

Published: 19 August 2021

Citation:

Joas J and Möhler E (2021) Maternal Bonding in Early Infancy Predicts Childrens' Social Competences in Preschool Age.

Front. Psychiatry 12:687535. doi: 10.3389/fpsyt.2021.687535

\section{Maternal Bonding in Early Infancy Predicts Childrens' Social Competences in Preschool Age}

\author{
Jens Joas and Eva Möhler* \\ Department of Child and Adolescent Psychiatry, Faculty of Medicine, Saarland University, Homburg, Germany
}

Background: There are many studies on mother-child-bonding with little theoretical doubt that better bonding may have a positive effect on further social development. However, there is hardly any empirical evidence. In particular, there is a lack prospective longitudinal studies.

Methods: As part of a longitudinal study, bonding was assessed in a community sample of 97 healthy mothers using the Postpartum Bonding Questionnaire (PBQ) 6 weeks after birth of their child. Social competencies in the offspring were assessed using the Self- and Other-oriented Social Competencies (SOCOMP) at 5.5 years of age. A potential correlation between bonding and social competencies was tested using Spearman Rank Correlation.

Results: Retention rate over 5.5 years was 77.23\%. Lower Maternal Bonding Impairment Scores 6 weeks postnatally were positively related to childrens' social competences at 5.5 years of age.

Conclusion: The present data confirm a positive and long-term influence of bonding on social skills and provide further evidence of the importance of parent child bonding for child development in general. This result should give reason to further investigate this relationship in depth, causally and at later points in time.

Keywords: bonding, social competences, social skills, child development, longitudinal study

\section{INTRODUCTION}

Bonding and early social experiences are assumed to be associated with a more healthy social and emotional development, to protect against stress and make children more resilient (1). Bonding is defined in developmental psychology as the emotional connection from parents to their children, in contrast to attachment, which is the emotional connection of the child toward its caregiver. The opportunity for the development of bonding is assumed to have its peak in the 1st min and hours after birth, especially in the close physical contact and the reactions of the helpless infant seeking comfort, protection, warmth and nourishment from the parents' behavior (2-4). This first phase is also postulated to be the "sensitive period" and to equally occur in most mammals (5). Newborns, placed on the mother's abdomen, can instinctively locate and suckle the maternal breast without assistance in their 1st hour of life via their sense of smell/pheromones (6-9).

Undoubtedly, mothers have a large part in establishing social contact with their infant (10), but the newborns are able to interact with her via eye contact, body language and thus in turn elicit linguistic utterances (11). The lack of skin contact with the mother in the first 2 hours after birth 
alone causes the infant's body temperature to be lower (12). After 1 year, according to Parent-Child-Early Relational Assessment (PCERA) video analyses, the infants tended to be more dysregulated and irritable, their social interactions with mothers were less substantial (also in terms of reciprocal emotional response) (13).

Mothers and infants with $16 \mathrm{~h}$ more physical contact shortly after birth showed more reluctance to leave their baby with another person compared to the control group about 4 weeks later during a standardized interview, a medical examination of the baby and a recorded bottle feeding (14). These mothers watched and mostly stood during the examination, tried to calm their infants more, performed more stroking and expressed significantly more eye contact. There have been numerous studies documenting positive and negative effects of a lack of motherinfant (skin) contact in the infant's 1st h (15). Not only was the body and skin temperature lower in children in cots compared to children with mothers, the glucose content in the blood was also lower and they cried and expended significantly more energy $(16,17)$. Even 20 min of skin contact was associated with a significant reduction in circulating beta-endorphin (18). After 4 postnatal hours, babies with increased physical contact show a majority of longer sleep, a calmer sleep state, more bending and fewer stretching movements (19). Babies who had a stable very low birth weight even showed improved lung function with direct contact in some cases (20).

Early maternal mind-mindedness ["to treat her infant as an individual with a mind rather than merely as a creature with needs that must be satisfied," (21)] also have been reported to be of influence on the social-cognitive development of her child, affecting the development of empathy skills (22). Social skills in turn, are described to be associated with mental and psychological health (23) as well as-in a negative associationwith a wide range of disorders such as anxiety (24), blood pressure (25), substance abuse (26), and problem behaviors such as juvenile delinquency (27). High social skills, on the other hand, have been shown to lead to higher financial and professional success (28). Similar to bonding or also bonding vs. attachment (3) there is a definition and demarcation problem with social competences (e.g., on social skills) (29). According to the literature, studies for attachment and its influence on social competences could be found frequently (30-32), whereas there seems to be a lack of studies regarding bonding and its influence on social skills. It has been described however, that pet bonding of young children, in contrast to simple pet presence, has a positive effect on their social competences and empathy (33). With regard to the methodological problems, the advantages and disadvantages of sociometric or observed recording of social competences in children, we refer e.g., to Foster and Richey (34).

In their review, Alves et al. (35) concluded that a long separation from the mother triggers anxiety and depression-like symptoms in rodents-and is reflected qualitatively and quantitatively in maternal behavior. In a study on foals, separated from their mothers for $1 \mathrm{~h}$, were less socially competent after 1 year, which corresponds to the prepubertal period of these animals. Additionally they were more aggressive and showed withdrawal tendencies (36).
So far however, there has been no study examining the impact of neonatal bonding on childrens' social competences in a prospective longitudinal design. Whether maternal bonding in the neonatal period is related to social competences of children at preschool age in humans is the subject of this study.

\section{MATERIALS AND METHODS}

\section{Study Design}

In the present study, mothers completed the Postpartum Bonding Questionnaire at 6 weeks after birth. At the age of 5.5 years, the social skills of her child were assessed with a standardized instrument, also based on the mother's assessment.

\section{Participants}

The voluntary sample recruited 2002 and 2003 by Möhler et al. (37) consisted of 101 healthy Caucasian mothers with singleton pregnancies. Inclusion criteria were infant weight over 2,500 g, gestational age $>37$ weeks, all APGAR scores $>7$ and, generally good health of the baby as evidenced by the first 3 postnatal examinations. The mothers were from urban and rural areas and have been recruited from 4 large local maternity units. Exclusion criteria were an inability to speak and read German, an acute psychiatric disorder of the mother, as well as the use of drugs or medication that pose a risk to the fetus, excessive smoking (more than 5 cigarettes/day) and alcohol consumption during pregnancy.

All participants read the participant information sheet and had the opportunity to ask questions. An informed consent form was read, signed and returned by all child custodians. All participants took part in the study voluntarily and could withdraw their participation at any time without giving a reason.

Of the original 101 mothers, 97 filled out the postpartum Bonding Questionnaire 6 weeks postnatally, 78 still responded after 5.5 years which corresponds to a response rate of $77.23 \%$. This sample also had to be adjusted for 1 outlier and another case due a high number (more than 1 missing value) of missing values, so that the final sample is 76 . If there was exactly 1 missing value in a questionnaire, the rounded individual subscale mean of the respective test has been used for this. This was necessary in 9 cases. The flow of participants can be found in Table 1 .

TABLE 1 | Flow of participants.

\begin{tabular}{lcc}
\hline & N & $\%$ \\
\hline N T0 & 101 & 100 \\
n T1 & 97 & 96.04 \\
Responded and take part T2 & 78 & 77.23 \\
Excluded as an outlier & 1 & 0.99 \\
Excluded due to too many missing values & 1 & 0.99 \\
Sample n T2 & 76 & 75.25 \\
\hline
\end{tabular}

TO, prenatal; T1, 6 weeks after birth; T2, 5.5 years after birth. 


\section{Measures}

The Postpartum Bonding Questionnaire (PBQ) (38) measures disturbances in the mother-child relationship based on self-report by the mother using a six-point Likert scale. The questionnaire, consisting of 25 items and 4 subscales (impaired bonding [12 items], rejection and anger [7 items], anxiety about care of the baby [4 items], risk of child abuse [2 items]) and a total score, has satisfactory interrater reliabilities (Pearson's $r$ $0.95,0.95,0.93,0.77)$, except for the 'risk of child abuse' scale. Similar in terms of sensitivity $(0.93,0.57,0.43,0.18$, in severe cases sensitivity $1.0,0.89,0.56,0.28)$. In its validation study (39), these values could be approximately replicated $(0.82,0.68,0.61$, 0.13 , in severe cases $0.93,0.88,0.64,0.2$ ).

The Social Competences Inventory SOCOMP (40) captures self- and other-oriented social skills in both its parent/teacher version, which was used because of its low threshold, multidimensionality and suitability for the young children in this study, and its child version. Its 25 items, assignable to the 3 main dimensions of self-oriented social skills, other-oriented social skills and positive peer relationships, are based on already established instruments such as the "Strenghts and Difficulties Questionaire" (scales of prosocial behavior and problems with peers) (SDQ) (41) or "The Social Skills Rating System" (SSRS) (42). Self-oriented competencies, defined as achieving one's own goals and satisfying needs in social interactions, are assessed via 10 items, which can be further divided into the subscales leadership, setting limits and social participation. Other-oriented competences, defined there as the extent to which gratifications and the goals of others are taken into account at the same time, are also surveyed by 10 items and offer the subscales prosocial behavior and cooperative behavior. The remaining 5 items of the positive peer relationships scale measure peer relationship quality. All items are rated using a three-point Likert scale. The internal consistency of the items of the parent version is medium to high (43).

\section{Statistical Analysis}

The data were analyzed with IBM SPSS Statistics, version 26. Due to the non-normal distribution of the data (K.-S.-Test: PBQ $p<0.001$; SOCOMP $p=0.02$ ), a Spearman Rank Correlation was calculated. A significance level of 0.05 was used for all statistical tests.

\section{RESULTS}

\section{Sample}

Characteristics of the sample are presented in Table 2. The mothers were aged between 19 and 45 years $(M=33.58$ years, $S D=4.07)$ at the first time of measurement, non-smokers, did not drink more than an occasional glass of wine or beer during pregnancy and had a term birth. The birth weight of the children ranged from $2,520 \mathrm{~g}$ to $4,500 \mathrm{~g}(M=3486.32, S D=421.15)$. $57.9 \%$ of the children were male, $42.1 \%$ female. All mothers were in a stable partnership with the child's father. $19.74 \%$ of them had a secondary school leaving certificate, $19.74 \%$ had a high school leaving certificate, $60.53 \%$ had a university degree and were thus educated above average.
TABLE 2 | Characteristics of sample $(n=76)$.

\begin{tabular}{lcccc}
\hline Characteristic & $\boldsymbol{M}$ & SD & Min. & Max. \\
\hline Age of mothers in years T1 & 33.58 & 4.07 & 19 & 45 \\
Birth weight child in grams & 3486.32 & 421.15 & 2,520 & 4,500 \\
Newborn gender & $\mathrm{n}$ & $\%$ & & \\
Male & 44 & 57.9 & & \\
Female & 32 & 42.1 & \\
School graduation (mother) & $\mathrm{n}$ & $\%$ & & \\
Secondary school & 15 & 19.74 & \\
High school & 15 & 19.74 & \\
University & 46 & 60.53 & \\
\hline
\end{tabular}

T1, 6 weeks after birth.

\section{Descriptive Analysis}

Figure 1 shows the distribution of the total PBQ scores $(M=$ $10.42, S D=7.01$ ) of the final sample. The auxiliary lines show that only 4 test persons meet or exceed the cut-off (purple line) of 26 for identifying some type of bonding disorder and no mother reaches the value of a maternal rejection (red line). Table 3 illustrates that the cut-off was only exceeded in eight cases in the impaired bonding scale.

Distribution of data regarding social competences in preschool age can be seen in Figure 2. No child falls below the provisional cut-off value for the total score, the lower limit of which was determined on the basis that each item was agreed to at least proportionally and the upper limit of which reflects the top $10 \%$. Two children lie exactly on the provisional cut-off value $(M=38.29, S D=4.41)$. For the majority of the sample, the social competences are therefore adequate to well-developed. Here, too, it is worth considering the respective subscales (Table 4). While almost a quarter (23.68\%) of the children have low self-oriented social competences and no child has conspicuously high values in this area, hardly one child (3.95\%) has a low level of other-oriented social competences and $44.74 \%$ have high values. The results for peer relationships are even more positive. There, only 1 child has a low, but more than half (53.95\%) have satisfactory social competencies.

The mothers' physical and psychological symptoms, assessed at both time points by the Symptom Checklist 90 revised [SCL90-R; original (44): german version (45)] showed a remarkably low level (Global severity index after 6 weeks: $M=0.21, S D=$ 0.15 ; after 5.5 years: $M=0.17, S D=0.18$ ), with regard to global severity index after 6 weeks only two mothers [T60 and T61], after 5.5 years only one mother [T65] scored above the cut off.

\section{Correlation of Maternal Bonding With Social Skills}

Even in this socially protected and well-adjusted sample, a Spearman Rank Correlation between the PBQ total scores and the SOCOMP total scores revealed a significant correlation (Table 5). High PBQ total scores (high bonding impairment) are therefore negatively related to SOCOMP total scores $[r s(74)=$ $-0.31, p=0.01]$. Less optimal mother-child bonding is shown to predict lower social skills in the child. According to Cohen 


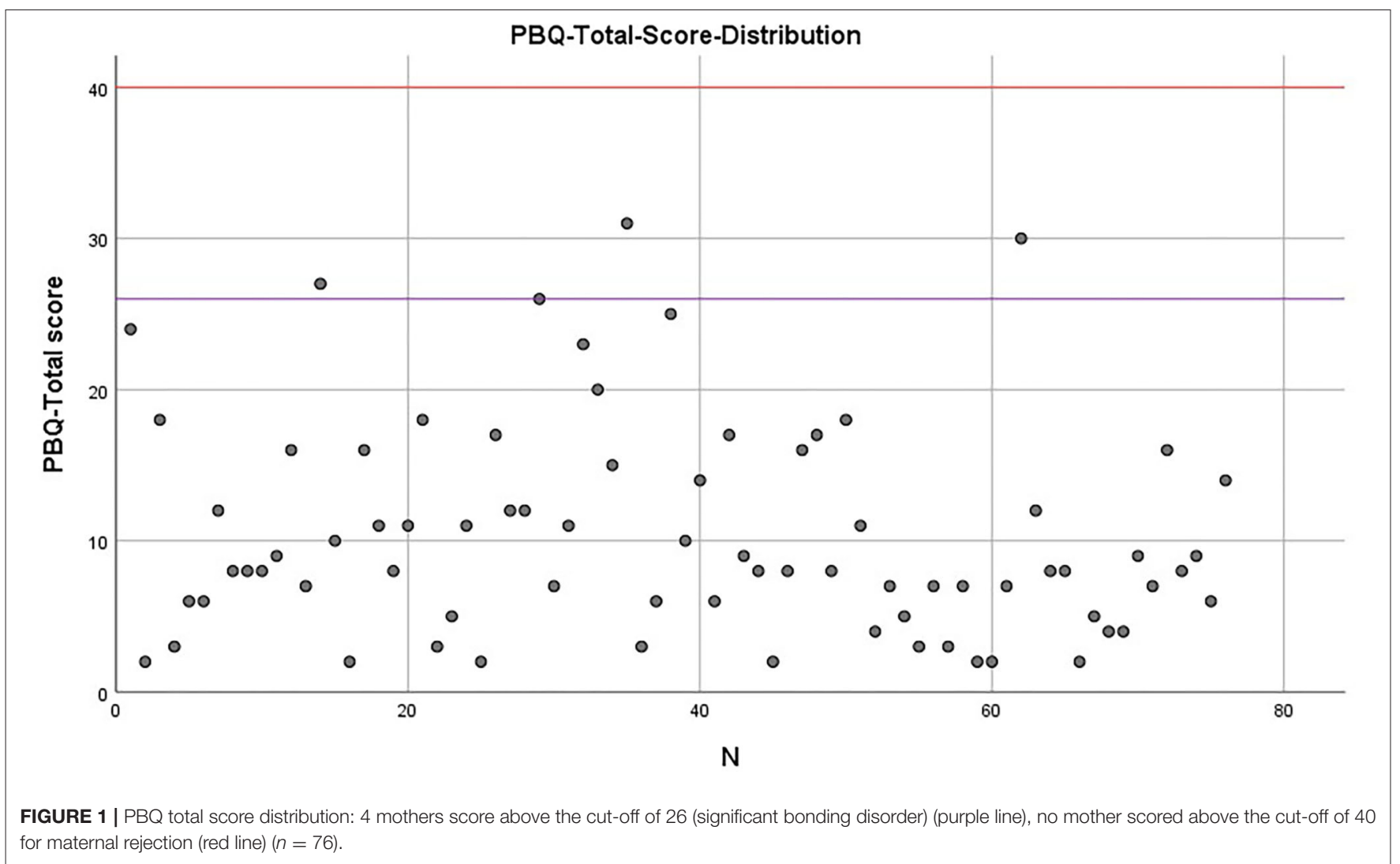

TABLE 3 | Descriptive statistics of PBQ results $(n=76)$.

\begin{tabular}{lccccc}
\hline & Total & $\begin{array}{c}\text { Impaired } \\
\text { bonding }\end{array}$ & $\begin{array}{c}\text { Rejection } \\
\text { and anger }\end{array}$ & $\begin{array}{c}\text { anxiety about risk of child } \\
\text { care of the } \\
\text { baby }\end{array}$ & \\
\hline Items & 25 & 12 & 7 & 4 & 2 \\
M & 10.42 & 5.86 & 2.11 & 2.33 & 0.13 \\
SD & 7.01 & 4.10 & 2.21 & 1.29 & 0.38 \\
Minimum & 2 & 0 & 0 & 0 & 0 \\
Maximum & 31 & 17 & 8 & 6 & 2 \\
Cut-off & 26 resp. 40 & 12 & 17 & 10 & 3 \\
n $>$ cut-off & 4 resp. 0 & 8 & 0 & 0 & 0
\end{tabular}

(46), we are consequently in the range of a moderate correlation $(r=0.30)$.

\section{DISCUSSION}

Our data in a healthy community sample indicate an early influence of maternal bonding on childrens' social skills in preschool age. The mechanisms behind this association are presumed to be interactional, however a genetic contribution to this association cannot be excluded. Unfortunately, there are only a few long-term studies with humans, but most of them show positive effects of early maternal bonding $(13,14)$. Prospective longitudinal studies with humans are difficult, not only from an ethical point of view, but also in general in this area, as there are many influencing variables (e.g., social events, interactions, also with peers, psychopathology, substance abuse). Our sample tried to control these factors with strict inclusion criteria. Long-term studies with animals underline our data showing the negative aspects of a lack of bonding [e.g., on social behavior (36)], even if they are not easily transferable to humans (47).

Defining social competences is difficult. There are also advantages and disadvantages in methodological recording (34). In our case, they were assessed sociometrically and based on mothers' judgements. Self-assessments, which we could have compared, were not yet available in this age group and observations would only have been possible via excerpts. Of course, social skills are not only influenced by bonding, but also by a variety of other factors. Dodge (48) considers social skills as an interaction between biologically determined abilities and environmental factors. On the side of biological factors temperament (49), temperamental surgency and emotion regulation (50) in particular but also malnutrition $(51,52)$ and genetic influences (53). On the environmental side especially culture (54) and family factors (e.g., involvement, communication, supportive Relationships, enable relationships $(55,56)$, psychopathology (57), maltreatment (58), single-parent and socioeconomic status (59).

Like social skills, bonding is also influenced by a number of different factors [e.g., parental behavior, nutrition (60), 


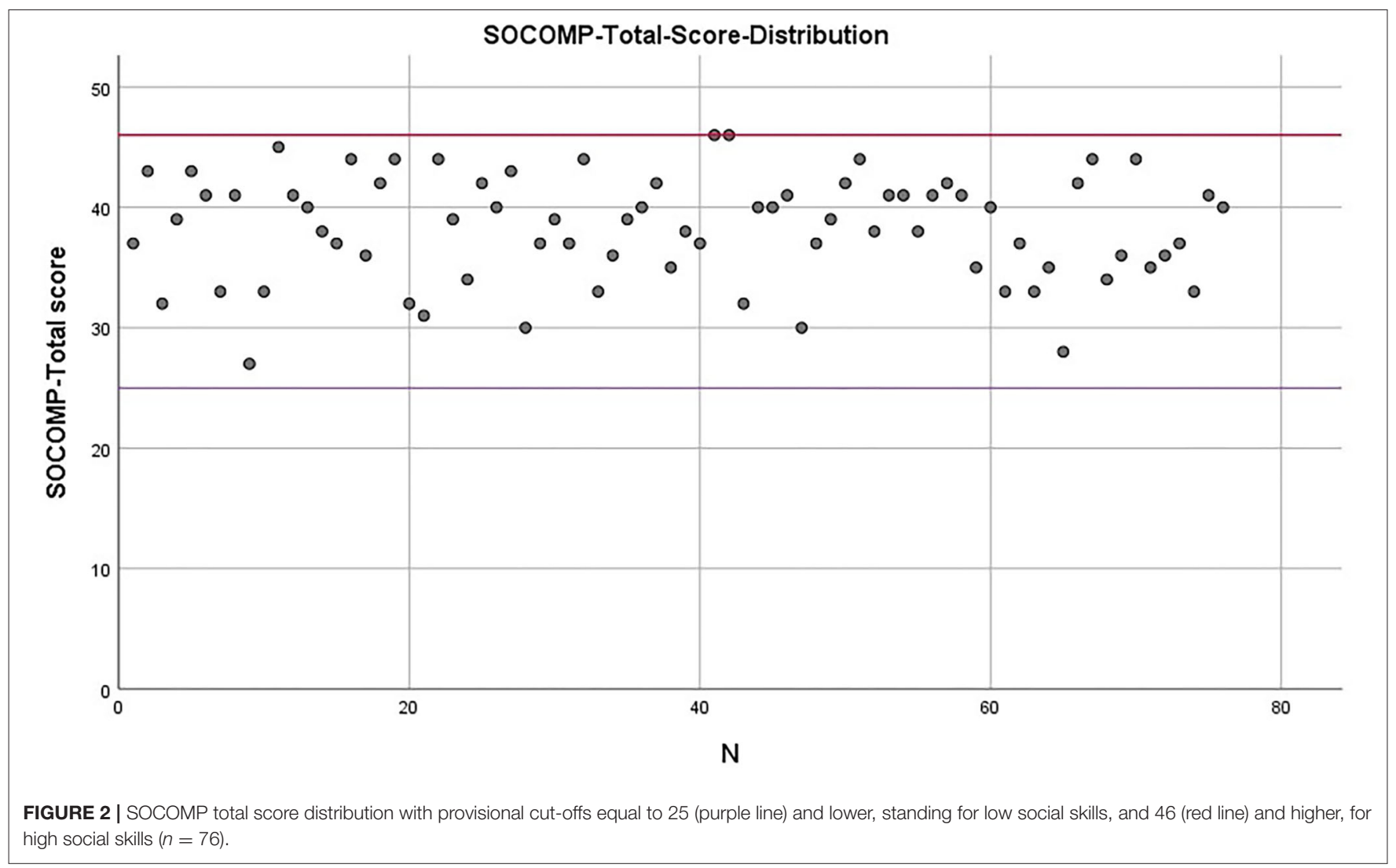

TABLE 4 | Descriptive statistics of SOCOMP-results $(n=76)$.

\begin{tabular}{lcccc}
\hline & Total & $\begin{array}{c}\text { Self-oriented } \\
\text { social skills }\end{array}$ & $\begin{array}{c}\text { Other- } \\
\text { oriented } \\
\text { social skills }\end{array}$ & $\begin{array}{c}\text { Positive } \\
\text { peer } \\
\text { relationships }\end{array}$ \\
\hline Items & 25 & 10 & 10 & 5 \\
M & 38.29 & 12.47 & 16.57 & 9.25 \\
SD & 4.41 & 2.24 & 2.77 & 1.10 \\
Minimum & 27 & 8 & 10 & 5 \\
Maximum & 46 & 17 & 20 & 10 \\
Provisional cut-off & $25 / 46$ & $10 / 18$ & $10 / 18$ & $5 / 10$ \\
n </> provisional cut-off & $0 / 2$ & $19 / 0$ & $3 / 34$ & $1 / 41$ \\
\hline
\end{tabular}

TABLE 5 | Spearman Rank Correlation of bonding impairment assessed 6 weeks after birth with social competencies assessed at 5.5 years.

\begin{tabular}{lccccc}
\hline Variable & $\boldsymbol{n}$ & $\boldsymbol{M}$ & SD & $\mathbf{1}$ & $\mathbf{2}$ \\
\hline 1. PBQ-Total score & 76 & 10.42 & 7.01 & & $-0.31^{*}$ \\
2. SOCOMP-Total score & 76 & 38.29 & 4.41 & $-0.31^{*}$ & \\
\hline
\end{tabular}

${ }^{*} p<0.05$.

maternal personality (61)]. As documented earlier, the shortterm effects of a lack of bonding are largely negative, but the fact that it can have even a long-term to lifelong influence on a connection with social skills and thus, as we know with regard to the positive function of social skills [ranging from school readiness (62) to academic success (63) and its protective function against developmental psychopathology (64)] seems considerable. This is meaningful because some studies found positive effects of bonding for a short time, e.g., a few days after birth, but which were no longer present weeks later (65) and which may cast doubt on the effectiveness of bonding. Interestingly, correlations with juvenile deliquence can be found for both poor bonding (66) and social skills (27). According to Mak (67) caring mothers who are perceived as warm and understanding are a protective factor against deliquence. In addition, there is evidence that paternal violence, physical abuse and sexual abuse by the father increased adolescents' sexual aggression, whereas bonding to the mother decreased it (68).

The influence of neuropeptides (especially oxytocin (6976) as one possible mediator of this association, also arginine vasopressin $[\mathrm{AVP}])$, an altered GABAA inhibitory system and steroids (especially oestrogens) in the first social phase on later behavior and emotion regulation has been documented extensively $(69-71,77)$. Oxytocin arguably stimulates maternal feelings (78), influences maternal behavior (79-83), promotes bonding $(84,85)$ and at the same time is itself derived from early social interaction $(1,86)$. Several studies using intranasal oxytocin administration show significant improvements in social skills (87) in the case of rats administered to the central amygdala (88), children and adolescents with autism spectrum disorders (89), others in case of children and adolescents with autism spectrum disorders not $(90,91)$. 
Another mediator of this association might be maternal psychopathology: it has been demonstrated, that psychopathology of the mother can have a negative impact on the quality of bonding with the child [e.g., postnatal anxiety (92), depression at 2 and 6 weeks as well as 4 months (93)]. The study by Galeshi et al. (94) also shows that anxiety, depression and unwanted pregnancy are influencing factors on mother-child bonding and suggests that early diagnosis and treatment of maternal anxiety and depression has a positive effect on bonding. Genetically similar depressive symptoms in children are in turn associated with deficient social skills and problems with peers (95). Conversely, a very high level of prosocial behavior, especially in the case of low social participation, can in contrast promote the development of emotional symptoms (96). Also, as data in our study are based on maternal report only, maternal depression could have lead to maternal perceptive distortions and as such, a more negative perception of bonding and social competences. Furthermore, Bonding has been shown to be related to maternal Psychopathology (93). However, in our psychosocially well-adjusted community sample mothers showed remarkably low levels in terms of psychopathology according to SCL-90-R-cut-off, therefore a distinct relation between bonding and social competences can still be assumed, although this association needs to be elucidated in further studies e.g., on mothers with a significant degree of psychopathology.

The majority of definitions of bonding emphasize the emotional component (3). In the case of babies, therefore, not only the physical satisfaction of needs should be taken into account, more importance should be attached to social interaction. Babies who lack social interaction may do not gain enough weight, become indifferent, listless, withdrawn and develop psychopathology (e.g., depression) (97).

All mothers in our sample were married to the childs' father and had rather good bonding qualities. Children were healthy full term births. It remains to elucidate whether the association demonstrated in this study can also be found in higher risk samples.

There is a lack of studies investigating whether interventions to promote mother-child bonding in early infancy improve the social skills of preschool-aged children.

\section{Strengths and Limitations of the Study}

Our results indicate the existence of a -theoretically assumed-relationship between bonding and social skills even in a psychosocially very well-adjusted and healthy community sample. Even in this sample, it is evident that successful bonding seems to increase the social competence of children 5.5 years

\section{REFERENCES}

1. Tops M, Koole SL, Ijzerman H, Buisman-Pijlman FTA. Why social attachment and oxytocin protect against addiction and stress: insights from the dynamics between ventral and dorsal corticostriatal systems. Pharmacol Biochem Behav. (2014) 119:39-48. doi: 10.1016/j.pbb.2013.07.015

2. Uphoff R, Näther A. Bonding - bindung von mutter und kind. Kinderkrankenschwester. (2017) 6:2-4. later. Also, with regard to the multitude of further factors that influence our social competences, the extent of the correlation seems considerable. One major limitation is the fact, that bonding as well as social competences were assessed in maternal judgment. Therefore, a general distortion of maternal perception cannot be excluded. Paternal variables were not assessed. Due to the specificity of the present sample, additional studies (including a clinical sample) are necessary to verify the causality of the relationship. The inclusion of other variables (e.g., ability to regulate emotions, anxiety, temperament, environmental influences, biological factors) would be meaningful in future long-term studies. With regard to the instruments, in order to be able to classify the distribution of the sample with the SOCOMP, provisional cut-off values were assigned, which may influence the results.

\section{DATA AVAILABILITY STATEMENT}

The raw data supporting the conclusions of this article will be made available by the authors, without undue reservation.

\section{ETHICS STATEMENT}

The studies involving human participants were reviewed and approved by University of Heidelberg, Medical School Ethics Committee. Written informed consent to participate in this study was provided by the participants' legal guardian/next of kin.

\section{AUTHOR CONTRIBUTIONS}

EM recruited participants and collected the data. JJ performed the statistical analysis and wrote the first draft of the manuscript. All authors had full access to all the data in the study and take responsibility for the integrity of the data and the accuracy of the data analysis. Furthermore, all authors read, gave feedback, and approved the submitted version.

\section{FUNDING}

This research was funded by the German Research Foundation (MO 978/1-1, Mo978/1-2 and Mo 978/5-1).

\section{ACKNOWLEDGMENTS}

We thank all participating mothers and children for their support and cooperation. 
Hunter RHF. Reproduction in Mammals and Man. Paris: Ellipses (1993). p. 553-65.

6. Blass EM \& Teicher MH. Suckling. Science. (1980) 210:1522. doi: 10.1126/science.6997992

7. Klaus MH. Mother and infant: early emotional ties. Pediatrics. (1998) 102:1244-6. doi: 10.1542/peds.102.5

8. Koepke JE, Bigelow AE. Observations of newborn suckling behavior. Infant Behav Dev. (1997) 20:93-98.

9. Varendi H, Porter RH, Winberg J. Does the newborn baby find the nipple by smell? Lancet. (1994) 344:989-90. doi: 10.1016/s0140-6736(94)91645-4

10. Klaus MH, Kennell JH, Plumb N, Zuehlke S. Human maternal behaviour at the first contact with her young. Pediatrics. (1970) 46:187-92.

11. Als H. Communication in infancy and early childhood: The newborn communicates. J Commun. (1997) 27:6673. doi: 10.1111/j.1460-2466.1977.tb01828.x

12. Bystrova K, Widström AM, Matthiesen AS, Ransjö-Arvidso AB, WellesNyström B, Wassberg C, et al. Skin-to-skin contact may reduce negative consequences of "the stress of being born": a study on temperature in newborn infants, subjected to different ward routines in St. Petersburg. Acta Paediatrica. (2003) 92:320-6. doi: 10.1080/08035250310009248

13. Bystrova $\mathrm{K}$, Ivanova V, Edhborg M, Matthiesen AS, Ransjö-Arvidson $\mathrm{AB}$, Mukhamedrakhimov $\mathrm{R}$, et al. Early contact versus separation: effects on mother-infant interaction one year later. Birth. (2009) 36:97109. doi: 10.1111/j.1523-536X.2009.00307.x

14. Klaus MH, Jerauld R, Kreger NC, et al. Maternal attachment. Importance of the first post-partum days. $N$ Engl J Med. (1972) 286:460-63. doi: 10.1056/nejm197203022860904

15. Winberg J. Mother and newborn baby: mutual regulation of physiology and behavior-a selective review. Dev Psychobiol. (2005) 47:217-29. doi: 10.1002/dev.20094

16. Christensson K, Siles C, Moreno L, Belaustegui A, De La Fuente P, Lagercrantz $\mathrm{H}$, et al. Temperature, metabolic adaptation and crying in healthy fullterm newborns cared for skin-to-skin or in a cot. Acta Paediatrica. (1992) 81:488-93. doi: 10.1111/j.1651-2227.1992.tb12280.x

17. Christensson K, Cabrera T, Christensson E, Uvnas-Moberg K, Winberg J. Separation distress call in the human neonate in the absence of maternal body contact. Acta Paediatr. (1995) 84:468-73. doi: 10.1111/j.1651-2227.1995.tb13676.x

18. Mooncey S, Giannakoulopoulos X, Glover V, Acolet D, Modi N. The effect of mother-infant skin-to-skin contact on plasma cortisol and $\beta$-endorphin concentrations in preterm newborns. Infant Behav Dev. (1997) 20:5537. doi: $10.1016 / \mathrm{S} 0163-6383(97) 90045-\mathrm{X}$

19. Ferber SG, Makhoul IR. The effect of skin-to-skin contact (kangaroo care) shortly after birth on the neurobehavioral responses of the term newborn: a randomized, controlled trial. Pediatrics. (2004) 113:85865. doi: $10.1542 /$ peds.113.4.858

20. Acolet D, Sleath K, Whitelaw A. Oxygenation, heart rate and temperature in very low birthweight infants during skin-toskin contact with their mothers. Acta Paediatr Scand. (1989) 78:189-93. doi: 10.1111/j.1651-2227.1989.tb11055.x

21. Meins E, Fernyhough C, Fradley E, Tuckey M. Rethinking maternal sensitivity: mothers' comments on infants' mental processes predict security of attachment at 12 months. J Child Psychol Psychiatry. (2001) 42:63748. doi: 10.1111/1469-7610.00759

22. Licata M, Kristen-Antonow S, Thoermer C, Sodian B. Die Bedeutung der frühen mütterlichen Mind-mindedness für die Entwicklung der Empathiefähigkeit von zweijährigen Kindern. Zeitschrift Entwicklungspsychol Pädagogische Psychol. (2013) 45:77-90. doi: 10.1026/0049-8637/a000082

23. Spitzberg, BH. Methods of interpersonal skills assessment. In: Greene JO, Burleson BR. Handbook of Communication and Social Interaction Skills. Hillsdale, NJ: Lawrence Erlbaum Associates Publishers. (2003) p. 93-134.

24. Fydrich T, Chambless DL, Perry KJ, Buergener F, Beazley MB. Behavioral assessment of social performance: A rating system for social phobia. Behav Res Ther. (1998) 36:995-1010. doi: 10.1016/S0005-7967(98)00069-2

25. Ewart CK, Taylor CB, Kraemer HC, Agras WS. Reducing blood pressure reactivity during interpersonal conflict: Effects of marital communication training. Behav Ther. (1984) 15:473-84. doi: 10.1016/S0005-7894(84)80050-7

26. Feldstein SW, Miller WR. Substance use and risk-taking among adolescents. $J$ Mental Health. (2006) 15:633-43. doi: 10.1080/09638230600998896
27. Laak J, Goede M, Aleva L, Brugman G, Leuven, M. Incarcerated adolescent girls: Personality, social competence, and delinquency. Adolescence. (2003) 38:251-65.

28. O'Neil HF, Allred K, Baker EL. Review of workforce readiness theoretical frameworks. In: O'Neil HF editor. Workforce Readiness: Competencies and Assessment. Mahwah, NJ: Lawrence Erlbaum Associates (1997). p. 229-54.

29. Dodge K, Pettit G, McClaskey C, Brown M, Gottman J. Social competence in children. Monograp Soc Res Child Dev. (1986). 51:i-85. doi: 10.2307/1165906

30. Rose-Krasnor L, Rubin KH, Booth CL, Coplan R. The relation of maternal directiveness and child attachment security to social competence in preschoolers. Int J Behav Dev. (1996) 19:309-25. doi: 10.1080/016502596385802

31. Cohn DA. Child-mother attachment of six-year-olds and social competence at school. Child Dev. (1990) 61:152-62. doi: 10.1111/j.1467-8624.1990.tb02768.x

32. Verissimo M, Santos AJ, Fernandes C, Vaughn, BE. Associations between attachment security and social competence in preschool children. MerrillPalmer Q. (2014) 60:5. doi: 10.13110/merrpalmquar1982.60.1.0080

33. Poresky RH, Hendrix C. Differential effects of pet presence and pet-bonding on young children. Psychol Rep. (1990) 67:51-4. doi: 10.2466/pr0.1990.67.1.51

34. Foster SL, Ritchey WL. Issues in the assessment of social competence in children. J Appl Behav Anal. (1979) 12:625-38. doi: 10.1901/jaba.1979.12-625

35. Alves RL, Portugal CC, Summavielle T, Barbosa F, Magalhães A. Maternal separation effects on mother rodents' behaviour: A systematic review. Neurosci Biobehav Rev. (2020) 117:98109. doi: 10.1016/j.neubiorev.2019.09.008

36. Henry S, Richard-Yris MA, Tordjman S, Hausberger M. Neonatal handling affects durably bonding and social development. PLOS ONE. (2009) 4:e5216. doi: 10.1371/journal.pone.0005216

37. Möhler E, Kagan J, Parzer P, Wiebel A, Resch F. Relation of behavioral inhibition to neonatal and infant cardiac activity, reactivity and habituation. Personal Individ Differ. (2006) 41:1349-58. doi 10.1016/j.paid.2006.05.008

38. Brockington IF, Oates J, George S, Turner D, Vostanis P, Sullivan M, et al. A screening questionnaire for mother-infant bonding disorders. Arch Women's Mental Health. (2001) 3:133-40. doi: 10.1007/s007370170010

39. Brockington IF, Fraser C, Wilson D. The postpartum bonding questionnaire: a validation. Arch Women's Mental Health. (2006) 9:233-42. doi: 10.1007/s00737-006-0132-1

40. Perren S. SOCOMP (Self-and other-oriented social Competences). Ein Fragebogen zur Erfassung von selbst- und fremdorientieren verhaltensbezogenen sozialen Kompetenzen. Zurich: Jacobs Center for Productive Youth Development (University of Zurich). (2007).

41. Goodman R. The strengths and difficulties questionnaire: a research note. J Child Psychol Psychiatry Allied Discipl. (1997) 38:581-6. doi: 10.1111/j.1469-7610.1997.tb01545.x

42. Gresham FM, Elliott SN. Social Skills Rating System. Circle Pines, MN: American Guidance Service (1990).

43. Perren S, Forrester-Knauss C, Alsaker FD. Self- and other-oriented social skills: Differential associations with children's mental health and bullying roles. J Educ Res Online. (2012) 4:99-123.

44. Derogatis LR. SCL-90-R, Administration, Scoring \& Procedures Manual-I for the R(evised) version. Baltimore: John Hopkins University School of Medicine (1977).

45. Franke GH. SCL-90-R - Die Symptom-Checkliste von L. R. Derogatis. (2nd $E d n$.). Göttingen: Beltz Test (2002).

46. Cohen J. Statistical Power Analysis for the Behavioral Sciences (2nd Edn.). Hillsdale, NJ: L. Erlbaum Associates (1988).

47. Gottlieb G, Lickliter R. The various roles of animal models in understanding human development. Soc Dev. (2004) 13:31125. doi: $10.1111 / j .1467-9507.2004 .000269 . x$

48. Dodge KA. A social information processing model of social competence in children. In: Perlmutter M, editor. The Minnesota Symposia on Child Psychology. Hillsdale, NJ: Erlbaum. (1986). p. 77-125.

49. Rispoli KM, McGoey KE, Koziol NA, Schreiber JB. The relation of parenting, child temperament, and attachment security in early childhood to social competence at school entry. J School Psychol. (2013) 51:64358. doi: 10.1016/j.jsp.2013.05.007

50. Dollar JM, Stifter CA. Temperamental surgency and emotion regulation as predictors of childhood social competence. J Experi Child Psychol. (2012) 112:178-94. doi: 10.1016/j.jecp.2012.02.004 
51. Upadhyay SK, Agarwal KN, Agarwal DK. Influence of malnutrition on social maturity, visual motor coordination \& memory in rural school children. Ind J Med Res. (1989) 90:320-7.

52. Ricciuti HN. Developmental consequences of malnutrition in early childhood. In: Lewis M, Rosenblum LA, editors. The Uncommon Child. Boston, MA: Springer US. (2019). p. 151-72.

53. Battaglia M, Michelini G, Pezzica E, Ogliari A, Fagnani C, Stazi M-A, et al. Shared genetic influences among childhood shyness, social competences, and cortical responses to emotions. J Experi Child Psychol. (2017) 160:6780. doi: 10.1016/j.jecp.2017.03.012

54. Hecht ML, Shin Y. Culture and social and emotional competencies. In: Durlak JA, Domitrovich CE, Weissberg RP, Gullotta TP, editors. Handbook of Social and Emotional Learning: Research and Practice. New York, NY: The Guilford Press. (2015). p. 50-64.

55. McWayne C, Hampton V, Fantuzzo J, Cohen HL, Sekino Y. A multivariate examination of parent involvement and the social and academic competencies of urban kindergarten children. Psychol Schools. (2004) 41:363-77. doi: 10.1002/pits.10163

56. Hillaker BD, Brophy-Herb HE, Villarruel FA, Haas BE. The contributions of parenting to social competencies and positive values in middle school youth: positive family communication, maintaining standards, and supportive family relationships. Family relation. Interdiscipl J Appl Family Sci. (2008) 57:591-601. doi: 10.1111/j.1741-3729.2008.00525.x

57. Eiden RD, Colder C, Edwards EP, Leonard KE. A longitudinal study of social competence among children of alcoholic and nonalcoholic parents: Role of parental psychopathology, parental warmth, and self-regulation. Psychol Addict Behav. (2009) 23:36-46. doi: 10.1037/a0014839

58. Fantuzzo JW, Weiss ADG, Atkins M, Meyers R, Noone M. A contextually relevant assessment of the impact of child maltreatment on the social competencies of low-income urban children. J Am Acad Child Adolesc Psychiatry. (1998) 37:1201-8. doi: 10.1097/00004583-199811000-00021

59. Guidubaldi J, Perry JD. Divorce, socioeconomic status, and children's cognitive-social competence at school entry. Am J Orthopsychiatry. (1984) 54:459-68. doi: 10.1111/j.1939-0025.1984.tb01511.x

60. Harfouche JK. Nutrition and public health. Psycho-social aspects of breast-feeding, including bonding. Food Nutr Bull. (1980) 2:1-5. doi: 10.1177/156482658000200109

61. Keller N, Medved V, Armano G. The influence of maternal personality and risk factors for impaired mother-infant bonding on breastfeeding duration. Breastfeed Med. (2016) 11:532-37. doi: 10.1089/bfm.2016.0093

62. Blair C. School readiness: Integrating cognition and emotion in a neurobiological conceptualization of children's functioning at school entry. Am Psychol. (2002) 57:111-27. doi: 10.1037/0003-066X.57.2.111

63. Lafavor T. Predictors of academic success in 9- to 11-year-old homeless children: the role of executive function, social competence, and emotional control. J Early Adolesc. (2017) 38:1236-64. doi: 10.1177/02724316166 78989

64. Huber L, Plötner M, Schmitz J. Social competence and psychopathology in early childhood: a systematic review. Eur Child Adolesc Psychiatry. (2019) 28:443-59. doi: 10.1007/s00787-018-1152-x

65. Carlsson SG, Fagerberg H, Horneman G, Hwang C-P, Larsson K, Rodholm $\mathrm{M}$, et al. Effects of various amounts of contact between mother and child on the mother's nursing behavior: A follow-up study. Infant Behav Dev. (1979) 2:209-14. doi: 10.1016/S0163-6383(79)80026-0

66. Pedersen W. Parental relations, mental health, and delinquency in adolescents. Adolescence. (1994) 29:975-90.

67. Mak, AS. Parental neglect and overprotection as risk factors in delinquency. Austr J Psychol. (1994) 46:107-11. doi: 10.1080/000495394082 59481

68. Kobayashi J, Sales BD, Becker JV, Figueredo AJ, Kaplan MS. Perceived parental deviance, parent-child bonding, child abuse, and child sexual aggression. Sex Abuse. (1995) 7:25-44. doi: 10.1007/BF02254872

69. Veenema AH. Toward understanding how early-life social experiences alter oxytocin- and vasopressin-regulated social behaviors. Hormones Behav. (2012) 61:304-12. doi: 10.1016/j.yhbeh.2011.12.002

70. Bales KL, Boone E, Epperson P, Hoffman G, Carter CS. Are behavioral effects of early experience mediated by oxytocin? Front Psychiatry. (2011) 2:24. doi: $10.3389 /$ fpsyt.2011.00024
71. Cushing BS, Kramer KM. Mechanisms underlying epigenetic effects of early social experience: the role of neuropeptides and steroids. Neurosci Biobehav Rev. (2005) 29:1089-105. doi: 10.1016/j.neubiorev.2005.04.001

72. Kim S, Soeken TA, Cromer SJ, Martinez SR, Hardy LR, Strathearn L. Oxytocin and postpartum depression: delivering on what's known and what's not. Brain Res. (2014) 1580:219-32. doi: 10.1016/j.brainres.2013.11.009

73. Levine A, Zagoory-Sharon O, Feldman R, Weller A. Oxytocin during pregnancy and early postpartum: individual patterns and maternal-fetal attachment. Peptides. (2007) 28:1162-9. doi: 10.1016/j.peptides.2007.04.016

74. Feldman R, Gordon I, Zagoory-Sharon O. Maternal and paternal plasma, salivary, and urinary oxytocin and parent-infant synchrony: considering stress and affiliation components of human bonding. Dev Sci. (2011) 14:75261. doi: 10.1111/j.1467-7687.2010.01021.x

75. Bales KL, Perkeybile AM. Developmental experiences and the oxytocin receptor system. Hormones Behav. (2012) 61:3139. doi: 10.1016/j.yhbeh.2011.12.013

76. Matthiesen AS, Ransjö-Arvidson AB, Nissen E, Uvnäs-Moberg K. Postpartum maternal oxytocin release by newborns: effects of infant hand massage and sucking. Birth. (2001) 28:13-9. doi: 10.1046/j.1523-536x.2001.00013.x

77. Caldji C, Francis D, Sharma S, Plotsky PM, Meaney MJ. The effects of early rearing environment on the development of GABAA and central benzodiazepine receptor levels and noveltyinduced fearfulness in the rat. Neuropsychopharmacology. (2000) 22:219-29. doi: 10.1016/S0893-133X(99)00110-4

78. Buckley SJ. Executive summary of hormonal physiology of childbearing: evidence and implications for women, babies, and maternity care. J Perinatal Educ. (2015) 24:145-53. doi: 10.1891/1058-1243.24.3.145

79. Feldman R, Weller A, Zagoory-Sharon O, Levine A. Evidence for a neuroendocrinological foundation of human affiliation: plasma oxytocin levels across pregnancy and the postpartum period predict mother-infant bonding. Psychol Sci. (2007) 18:965-70. doi: 10.1111/j.1467-9280.2007.02010.x

80. Gordon I, Zagoory-Sharon O, Leckman JF, Feldman R. Oxytocin, cortisol, and triadic family interactions. Physiol Behav. (2010) 101:679-84. doi: 10.1016/j.physbeh.2010.08.008

81. Atzil S, Hendler T, Zagoory-Sharon O, Winetraub Y, Feldman R. Synchrony and specificity in the maternal and the paternal brain: relations to oxytocin and vasopressin. J Am Acad Child Adolesc Psychiatry. (2012) 51:798811. doi: 10.1016/j.jaac.2012.06.008

82. Feldman R, Gordon I, Influs $M$, Gutbir T, Ebstein RP. Parental oxytocin and early caregiving jointly shape children's oxytocin response and social reciprocity. Neuropsychopharmacology. (2013) 38:1154-62. doi: 10.1038/npp.2013.22

83. Kim S, Fonagy P, Koos O, Dorsett K, Strathearn L. Maternal oxytocin response predicts mother-to-infant gaze. Brain Res. (2014) 1580:13342. doi: 10.1016/j.brainres.2013.10.050

84. Taylor AE, Lee HE, Buisman-Pijlman FTA. Oxytocin treatment in paediatric populations. Front Behav Neurosci. (2014) 8:360. doi: $10.3389 /$ fnbeh.2014.00360

85. Olff M, Frijling JL, Kubzansky LD, Bradley B, Ellenbogen MA, Cardoso $\mathrm{C}$, et al. The role of oxytocin in social bonding, stress regulation and mental health: an update on the moderating effects of context and interindividual differences. Psychoneuroendocrinology. (2013) 38:188394. doi: 10.1016/j.psyneuen.2013.06.019

86. Wismer Fries AB, Ziegler TE, Kurian JR, Jacoris S, Pollak SD. Early experience in humans is associated with changes in neuropeptides critical for regulating social behavior. Proc Natl Acad Sci USA. (2005) 102:1723740. doi: $10.1073 /$ pnas. 0504767102

87. Hall SS, Lightbody AA, McCarthy BE, Parker KJ, Reiss AL. Effects of intranasal oxytocin on social anxiety in males with fragile X syndrome. Psychoneuroendocrinology. (2012) 37:50918. doi: 10.1016/j.psyneuen.2011.07.020

88. Lee PR, Brady DL, Shapiro RA, Dorsa DM, Koenig JI. Prenatal stress generates deficits in rat social behavior: Reversal by oxytocin. Brain Res. (2007) 1156:152-67. doi: 10.1016/j.brainres.2007.04.042

89. Gordon I, Vander Wyk BC, Bennett RH, Cordeaux C, Lucas MV, Eilbott JA, et al. Oxytocin enhances brain function in children with autism. Proc Natl Acad Sci USA. (2013) 110:20953-8. doi: 10.1073/pnas.1312857110 
90. Dadds MR, MacDonald E, Cauchi A, Williams K, Levy F, Brennan J. Nasal oxytocin for social deficits in childhood autism: a randomized controlled trial. J Autism Dev Disord. (2014) 44:521-31. doi: 10.1007/s10803-013-1899-3

91. Guastella AJ, Gray KM, Rinehart NJ, Alvares GA, Tonge BJ, Hickie IB, et al. The effects of a course of intranasal oxytocin on social behaviors in youth diagnosed with autism spectrum disorders: a randomized controlled trial. J Child Psychol Psychiatry. (2014) 56:444-52. doi: 10.1111/jcpp. 12305

92. Tietz A, Zietlow AL, Reck C. Maternal bonding in mothers with postpartum anxiety disorder: the crucial role of subclinical depressive symptoms and maternal avoidance behaviour. Arch Women's Mental Health. (2014) 17:43342. doi: 10.1007/s00737-014-0423-X

93. Moehler E, Brunner R, Wiebel A, Reck C, Resch F. Maternal depressive symptoms in the postnatal period are associated with long-term impairment of mother-child bonding. Arch Women's Mental Health. (2006) 9:2738. doi: 10.1007/s00737-006-0149-5

94. Galeshi M, Mirghafourvand M, Alizadeh-Sharajabad F, Sanaati F. Predictors of Mother-Child Bonding. Hayat: Journal of School of Nursing and Midwifery, Tehran University of Medical Sciences (2016).

95. Perren S, Alsaker F. Depressive symptoms from kindergarten to early school age: Longitudinal associations with social skills deficits and peer victimization. Child Adolesc Psychiatry Mental Health. (2009) 3:28. doi: 10.1186/1753-2000-3-28
96. Groeben M, Perren S, Stadelmann S, von Klitzing K. Emotional symptoms from kindergarten to middle childhood: associations with self- and other-oriented social skills. Eur Child Adolesc Psychiatry. (2011) 20:315. doi: 10.1007/s00787-010-0139-Z

97. Clarke-Stewart A, Koch JB. Children: Development Through Adolescence. New York, NY: Wiley \& Sons (1983).

Conflict of Interest: The authors declare that the research was conducted in the absence of any commercial or financial relationships that could be construed as a potential conflict of interest.

Publisher's Note: All claims expressed in this article are solely those of the authors and do not necessarily represent those of their affiliated organizations, or those of the publisher, the editors and the reviewers. Any product that may be evaluated in this article, or claim that may be made by its manufacturer, is not guaranteed or endorsed by the publisher.

Copyright (c) 2021 Joas and Möhler. This is an open-access article distributed under the terms of the Creative Commons Attribution License (CC BY). The use, distribution or reproduction in other forums is permitted, provided the original author(s) and the copyright owner(s) are credited and that the original publication in this journal is cited, in accordance with accepted academic practice. No use, distribution or reproduction is permitted which does not comply with these terms. 